\title{
The dissolution of apatite by phosphate-solubilizing microorganisms in soil: A balance between $P$ supply and toxicity
}

\author{
ZHEN LI ${ }^{1}$, MU SU ${ }^{2}$ AND XIAOQING SHAO ${ }^{3}$ \\ ${ }^{1}$ College of Resources and Environmental Sciences \\ ${ }^{2}$ Nanjing Agricultural University \\ ${ }^{3}$ College of Resources and Environmental Sciences, Nanjing \\ Agricultural University \\ Presenting Author: lizhen@njau.edu.cn
}

Apatite is the largest phosphorous reservoir on Earth. However, due to its low solubility, dissolved $\mathrm{P}$ is severely deficient in soil. Soil microorganisms play a significant role in $\mathrm{P}$ dissolution via excretion of organic acids and enzymes. We studied the bioweathering of fluorapatite by a typical phosphatesolubilizing fungus, Aspergillus niger. A. niger secrets organic acids and which enhance $\mathrm{P}$ release from apatite, leading to increased microbial growth. However, a simultaneous release of fluorine (F) causes toxicity to A. niger and significantly lowers the phosphate-solubilizing process. Additionally, the solubility of apatite is also limited by the abundance of carbonate and goethite, via $\mathrm{pH}$ buffering and production of reactive oxygen, respectively. The decreases in both the amount of biomass and the respiration rate of $A$. niger confirm the strong inhibitory effect on the microorganisms. Meanwhile, the solubility of organic phosphate is also degraded due to the low secretion of phosphatase and phytase. Therefore, even though phosphatesolubilizing microorganisms can facilitate $\mathrm{P}$ release, its solubilizing potential is constrained by $\mathrm{F}$ and some typical soil minerals. These toxicities might account for the low $\mathrm{P}$ availability in soil. 